\title{
SEXUALIDADE, GÊNERO E EDUCAÇÃO: NOVOS OLHARES
}

\author{
Ana Paula COSTA ${ }^{1}$ \\ Anne Caroline Mariank A. SCALIA ${ }^{2}$ \\ Regina Celia BEDIN ${ }^{3}$ \\ Shirley Romera dos SANTOS ${ }^{4}$
}

\begin{abstract}
RESUMO: Esta pesquisa pretende expor a importância e necessidade da formação de profissionais da educação quanto às temáticas sobre sexualidade, relações de gênero e sua compreensão no contexto escolar. Objetivou-se sensibilizar e gerar questionamentos de professores da Rede de Ensino levando-os a refletir o caráter histórico-social e mutável dos conceitos das temáticas citadas. A partir de oficina pedagógica com estes profissionais promoveu-se apresentações teóricas, exposição e discussão de situações cotidianas ao âmbito escolar relacionadas as temáticas trabalhadas. Partindo da compreensão que sexualidade e gênero são construções histórico-sociais, considerou-se que essas duas instâncias estão dentro da instituição educacional, sendo que as relações sociais existentes na escola produzem representações de sexualidade e relações de gênero que devem ser analisadas para que não ocorra a perpetuação de preconceitos e estereótipos que geram situações negativas entre meninos e meninas. Pensando sobre essas questões, percebeu-se a necessidade de formação nas temáticas de sexualidade e relações de gênero para pessoas que atuam diretamente com o ensino e lidam no cotidiano escolar com entraves relacionados a essas temáticas. A partir dessas intervenções notou-se que a maioria dos participantes conseguiu refletir sobre as questões levantadas ultrapassando não apenas a visão biológica, mas percebendo no enfoque das temáticas, possibilidades de prática diária no âmbito escolar.
\end{abstract}

PALAVRAS-CHAVE: Sexualidade. Gênero. Orientação Sexual. Escola.

\section{Introdução}

Por mais que a sexualidade seja uma temática que na escola se vincule às aulas de ciências ou então de educação física, é necessário considerar sua vertente social, e, sobretudo, histórica.

Quando afirmamos que a sexualidade é uma construção social, compartilhamos da idéia de Jeffrey Weeks (2000, p.40) de que esta é “[...] uma invenção social, a qual,

\footnotetext{
${ }^{1}$ UNESP - Universidade Estadual Paulista. Faculdade de Ciências e Letras - Departamento de Psicologia da Educação - Núcleo de Estudos da Sexualidade (NUSEX). Araraquara - SP - Brasil. 14800-901 anppessoa@yahoo.com.br

${ }^{2}$ UNESP - Universidade Estadual Paulista. Faculdade de Ciências e Letras - Departamento de Psicologia da Educação - Núcleo de Estudos da Sexualidade (NUSEX). Araraquara - SP - Brasil. 14800-901 sapidemens@yahoo.com.br

${ }^{3}$ Mestranda em Educação Escolar. UNESP - Universidade Estadual Paulista. Faculdade de Ciências e Letras Pós-Graduação em Educação Escolar - Núcleo de Estudos da Sexualidade (NUSEX). Araraquara - SP - Brasil. 14800-901 - redacelita@hotmail.com

${ }^{4}$ UNESP - Universidade Estadual Paulista. Faculdade de Ciências e Letras - Departamento de Psicologia da Educação - Núcleo de Estudos da Sexualidade (NUSEX).. Araraquara - SP - Brasil. 14800-901 shirleyromera@yahoo.com.br
} 
naturalmente, tem base nas possibilidades do corpo: o sentido e o peso que lhe atribuímos são, entretanto, modelados em situações sociais concretas”. Em outras palavras, isso significa que a sexualidade é um conceito mutável, que sofre modificações e variações em tempos e espaços históricos diferentes.

Michel Foucault (1988, p.100) é um dos expoentes que enfatiza a historicidade da sexualidade. Para este autor,

\begin{abstract}
A sexualidade é o nome que se pode dar a um dispositivo histórico: não a uma realidade subterrânea que se apreende com dificuldades, mas a grande rede de superfície em que a estimulação dos corpos, a intensificação dos prazeres, a incitação do discurso, a formação do conhecimento, o reforço dos controles e das resistências encadeiam-se uns ao outros, segundo algumas grandes estratégias do saber e dos poderes.
\end{abstract}

A compreensão da sexualidade enquanto dispositivo histórico indica que este conceito é também uma construção discursiva, uma vez que se constitui através de enunciados de várias instituições, como exemplo, a família, a religião, a escola, os recursos midiáticos, a política entre outras.

Esses discursos, por sua vez, emanam poderes sobre aqueles/as a que são dirigidos. No entanto, como afirma Foucault, o poder destas instituições sobre a sexualidade, não é um poder que pune, mas sim que propaga discursos que a incita e ao mesmo tempo a controla. É como se tivéssemos que falar de sexo, só que de forma sigilosa, ou melhor, em segredo. Deste modo, Foucault afirma que o poder que alavanca a sociedade moderna é de ordem positiva, já que é se exerce sem que possamos vê-lo, e é produtivo, uma vez que se reparte em micropoderes.

A sexualidade, portanto, é uma das estratégias desse poder positivo e múltiplo. Para Foucault, vai ser através de quatro mecanismos que a sexualidade, a partir do século XVIII, vai exercer poder sobre os sujeitos. São estes a "histerização do corpo da mulher", “pedagogização do sexo das crianças”, “socialização das condutas de procriação” e “psiquiatrização do prazer perverso”. Observa-se que três sujeitos passam a fazer parte do controle sobre a sexualidade, ou seja, a mulher, a criança e o homossexual.

A idéia de Foucault sobre a sexualidade só retifica as diversas roupagens que esta assume ao longo da história, bem como seu caráter mutável. É neste contexto que práticas sexuais indemissíveis no passado são aceitas no presente e vice-versa. Portanto,

[...] a história, enquanto disciplina e ciência, se torna uma grande aliada, uma vez que vem nos mostrar nossas diversas e também desconhecidas maneiras 
de lidar com a sexualidade. Assim, o que dizer, por exemplo, da pederastia grega na Grécia antiga? Da relação de passividade e atividade na Antigüidade romana? Da idéia de sexualidade infantil que data do século XX com Freud? Da concepção de homossexualidade como patologia (século XIX) e sua retirada da Classificação Internacional de Doenças (CID-10) somente em 1992? Do hermafrodita Herculine Barbin, estudado e citado por Foucault (1982 apud Weeks, 2000), por não apresentar a ligação esperada entre o sexo corporal e a identidade de gênero? (COSTA; RIBEIRO, 2008, p.02).

Além da dimensão histórica que abarca a composição da sexualidade, devemos levar em conta também que para entendê-la faz-se necessário pensar também na seguinte prerrogativa, ou seja, a de que a maneira como nos entendemos sexualmente é igualmente perpassada pela forma como nos entendemos enquanto homens e mulheres. Neste sentido, o conceito de gênero emerge, uma vez que a masculinidade e a feminilidade fazem parte da constituição do sujeito.

Joan Scott (1995, p.14) é uma das autoras que propõe o uso deste conceito como uma categoria de análise. Para esta autora, “[...] um elemento constitutivo de relações sociais fundadas sobre as diferenças percebidas entre os sexos, e o gênero é um primeiro modo de dar significado às relações de poder.”

Em outras palavras, o gênero é um modo de compreender mais claramente as relações existentes entre homens e mulheres e assim diluir preconceitos, já que como categoria de análise nos fornece elementos para questionarmos algumas normas e condutas naturalmente atribuídas ao feminino e ao masculino.

Segundo Scott, a primeira parte do conceito de gênero é constituída por quatro partes: 1) os símbolos que nos fornece modelos para sermos mulheres e homens adequados e inadequados para a sociedade; 2) normas que afirmam e negam os modelos de feminilidades e masculinidade; 3) o papel das instituições sociais no reforço da composição binária do gênero, ou seja, ou é masculino ou feminino; 4) as identidades subjetivas, as quais revelam que nem todas as imposições aos homens e às mulheres se sucedem da mesma forma, pois além da sexualidade, o gênero também mantém interseções com categorias como, raça, religião, classe social, nacionalidade entre outras.

Já a outra parte do conceito de gênero elaborado por Scott evidencia que as relações de gênero estão emersas ao poder, o que significa que o gênero, além de organizar a sociedade, dá inteligibilidade ao sujeito. Portanto, 
meio do qual, o poder é articulado. O gênero não é o único campo, mas ele parece ter constituído um meio persistente e recorrente de dar eficácia à significação do poder no Ocidente [...] Estabelecidos como um conjunto de objetivos e referências, os conceitos de gênero estruturam a percepção e a organização concreta e simbólica de toda a vida social. Na medida em que estas referências estabelecem distribuições de poder (um controle ou um acesso diferencial às fontes materiais e simbólicas), o gênero torna-se envolvido na concepção e na construção de poder em si mesmo. (SCOTT, 1995, p. 16).

Enquanto construções sociais, sexualidade e gênero são duas instâncias engendradas também pela escola, uma das instituições sociais que compõem a sociedade. Deste modo, as relações sociais existentes na escola produzem representações de sexualidade e relações de gênero que devem ser analisadas, pois em sua maior parte reproduzem preconceitos e estereótipos que geram situações negativas entre meninos e meninas.

Guacira Lopes Louro (2000) diz que a escola é uma das instâncias que propaga o que nomeia de pedagogias da sexualidade. Segundo esta autora, a pedagogia a que se refere diz respeito às normas, regras e condutas que são estipuladas como aceitas e não aceitas pela sociedade em relação ao sexo. A escola, para Louro (2000, p. 25), seria, portanto, uma dessas instituições que reforçam “[...] um investimento que, freqüentemente, aparece de forma articulada, reiterando identidades e práticas hegemônicas, enquanto subordina, nega ou recusa outras identidades e práticas.”

Neste contexto, é necessário pensarmos sobre algumas de nossas práticas educativas, já que podemos estar reforçando preconceitos sexuais e de gênero. Esses preconceitos podem vir revestidos de frases, atitudes e naturalização de situações que para nós parece corriqueira, como exemplo, afirmar que "menino não chora” ou então que “isso não é conduta de menina”. Faz-se importante orientar sexualmente nossos/as alunos, de maneira de que estes possam usufruir da sexualidade e das relações de gênero de forma prazerosa.

Autores que têm trabalhado com a questão da educação sexual (MAIA, 2004; MELO; POCOVI, 2002; FIGUEIRÓ, 2004, 2007) mostram a necessidade de se realizar estudos e pesquisas que dêem subsídios para a implantação de programas de orientação sexual para crianças, adolescentes e professores/as. Os Parâmetros Curriculares Nacionais (PCNs), com os temas transversais, destacaram a sexualidade e a orientação sexual como temáticas relevantes para discussão nos estabelecimentos de ensino. Por outro lado, a escola se tornou palco onde a sexualidade se manifesta com todo o seu vigor, mas encontra a indiferença, a negação e o preconceito quando foge da norma culturalmente estabelecida. 
Sempre que interagimos com uma pessoa, seja ela, criança, adolescente, adulto ou idoso, e lhe ensinamos algo (mesmo que não intencionalmente) a respeito da sexualidade, do corpo e do relacionamento humano, estamos educando sexualmente ${ }^{5}$. Assim, ensinamos por meio de nossas atitudes, de nossos exemplos, de nossa forma de nos relacionarmos com o outro e de como nos portamos como homens ou como mulheres. (FIGUEIRÓ, 2007, p.26).

O campo da sexualidade e da educação sexual, com ênfase nas relações de gênero, constitui espaço importante para a efetivação de propostas concretas de ação em que se combata a discriminação, o preconceito e a violência, tanto simbólica quanto real. Desta forma, precisamos perceber a orientação sexual como um elemento integrante do processo de construção de uma cidadania ativa. Ou seja, além da preocupação com o desenvolvimento de ações educativas voltadas para que os/as professores/as entendam a importância de se respeitar e valorizar a diversidade sexual e a igualdade de gênero, precisamos levar em conta que a inclusão social somente será completa se dela fizer parte a inclusão sexual.

Orientar sexualmente é atuar como facilitador e não apenas como um expositor de idéias ou um doutrinador (RIBEIRO; REIS, 2005), buscando ser um agente transformador e multiplicador de valores como qualquer outro educador. Por este caminho perpassa o paradigma de uma educação sexual emancipatória, que cria espaços para debater dúvidas e angústias, reflete não apenas sobre valores e conflitos, mas questiona tabus e preconceitos. Uma orientação sexual, portanto, que busca reconstruir inicialmente concepções internas para que depois se espraie para o coletivo, que não peque na busca de receitas, mas desperte a consciência crítica, possibilitando aos indivíduos escolherem caminhos sem medos, valorizando as diversas relações sociais, buscando o “[...] desenvolvimento pessoal do ser humano como um ser corporificado, sexuado, contribuindo na busca de uma cidadania para todos.” (MELO; POCOVI, 2002, p.38).

É preciso, sobretudo, e aí já vai um destes saberes indispensáveis, que o formando, desde o princípio mesmo de sua experiência formadora, assumindo-se como sujeito também da produção do saber, se convença definitivamente de que ensinar não é transferir conhecimento, mas criar as possibilidades para a sua produção ou a sua construção. [...] quem forma se forma e re-forma ao formar e quem é formado forma-se e

\footnotetext{
${ }^{5}$ A autora não considera em seus estudos a nomenclatura Orientação Sexual tal como as autoras deste artigo. Para esta, a educação sexual divide-se em dois tipos: informal e formal. A primeira corresponde à maneira "[...] como lidamos, no dia-a-dia, com as atuações que envolvem a sexualidade; nesses momentos, passamos uma forma positiva ou negativa da sexualidade e por isso, podemos dizer que estamos educando.” Já a educação sexual formal "[...] consiste num trabalho intencional, de ensino sobre as questões da sexualidade [...]" (FIGUEIRÓ, 2007, p.26) o que se assemelha ao entendimento que temos do termo Orientação Sexual utilizado neste artigo.
} 
forma ao ser formado. É nesse sentido que ensinar não é transferir conhecimentos, conteúdos nem formar é ação pela qual um sujeito criador dá forma, estilo ou alma a um corpo indeciso e acomodado. Não há docência sem discência, as duas se explicam e seus sujeitos, apesar das diferenças que os conotam, não se reduzam à condição de objeto, um do outro. (FREIRE, 1998, p.24-25).

A qualidade das relações humanas estabelecidas entre professor/a e alunos/as é a grande educadora ou deseducadora sexual na escola. Se essa qualidade foi construída por um/a professor/a que, além de respeitar, aceitar e gostar de seus/as alunos/as e do seu trabalho pedagógico, gosta de si mesmo e se conhece, tenta superar seus limites, medos e tabus, é aberto a mudanças, à revisão dos resquícios de uma educação sexual repressora e busca permanentemente compreender a complexidade da sexualidade humana, teremos, com certeza, um ambiente de educação sexual compreensiva.

Desta forma, procuramos discutir neste artigo são as manifestações da sexualidade e da aprendizagem de gênero na escola e a necessidade de uma orientação sexual ${ }^{6}$ emancipatória, através do aperfeiçoamento da formação docente. Dito isto, a orientação sexual no âmbito escolar traz benefícios a todos os envolvidos, mas tem como meta maior, assim como tudo na escola, atender nossas crianças e nossos adolescentes em seu direito a uma educação integral, que, para ser entendida, não pode negar a sexualidade e as questões de gênero. Mas quem educa o/a educador/a? Precisamos antes de qualquer coisa, propiciar aos/as professores/as condições para que estes/as se percebam como seres sexuados no mundo, em permanente processo de educação, inclusive de educação sexual. Precisamos trazê-los para esta educação sexual emancipatória, fazendo-os refletir sobre os costumes repetidos acriticamente em nossa sociedade, questionando-os/as se os tabus, preconceitos e medos servem ainda para a realidade em que vivemos, tentando levar estes/as professores/as a falarem com naturalidade sobre a temática sexualidade.

\section{Objetivos}

Em vista que os PCNs (Parâmetros Curriculares Nacionais) propõem o trabalho de Orientação Sexual como tema transversal pressupõe-se a necessidade de formação de profissionais da educação quanto ao tema de sexualidade e relações de gênero, uma vez que

\footnotetext{
${ }^{6}$ Ainda que autores consultados usassem a expressão "Educação Sexual”, optaremos por substituí-la por "Orientação Sexual”, quando estivermos nos referindo a programas de orientação. Entendemos que os programas de orientação sexual se incluem no processo de educação sexual mais amplo, porém, julgamos mais adequado a escolha de "orientação" para enfatizar quando se trata de um programa formalizado em um ambiente específico e quando se trata de um processo educacional abrangente do desenvolvimento humano, histórico e cultural.
} 
esses temas perpassam a rotina escolar. Desta forma, os objetivos específicos deste trabalho são:

- Sensibilizar esses/as futuros educadores/as ou aqueles/as que já atuam na área da educação sobre sexualidade e relações de gênero na escola;

- Proporcionar questionamentos acerca da idéia de que as concepções e comportamentos sexuais são perpassados pelas representações de gênero.

Assim, o objetivo geral de nossos esforços é refletir, a partir desta sensibilização e destes questionamentos, o caráter histórico-social e mutável dos conceitos de sexualidade e relações de gênero.

\section{Procedimentos metodológicos}

Para "tatear" as questões levantadas, partimos da idéia conceitual de sexualidade e gênero apresentada pelas formulações teóricas de Michael Foucault (1988) e Joan Scott (1995). Tal procedimento objetivava trabalhar com questões de sexualidade e relações de gênero na intersecção com o espaço escolar, visando informações e conscientizações sobre questões sexuais e os papéis que “a priori” são atribuídos a homens e a mulheres.

O projeto girou em torno da apresentação teórica a partir de slides, exposição e discussão de situações cotidianas que envolvem sexualidade e relações de gênero, usando para isto o livro "Meninas e meninos na escola: um encontro possível?” de Fabiana Cristina de Souza (2006) e a elaboração de atividades pedagógicas por parte dos professores participantes que envolvessem os temas abordados a partir da indicação de livros infantis trabalhados em escola pública, ensino fundamental, em projetos como "Prevenção também se ensina”. Foram utilizados 2 livros “Mamãe botou um ovo” (1993) e "Cabelinhos nuns lugares engraçados” (1999) de Babette Colle.

A princípio foram estipulados 2 encontros a serem realizados semanalmente com duração de 2 horas cada. O público alvo elencado foi um grupo de estudos, formado basicamente por professores da rede, situado dentro de uma Universidade Pública do Estado de São Paulo. Como não houve, por parte dos pesquisadores, obrigatoriedade de participação no devido estudo, colaboraram com nosso projeto 9 participantes dos 15 envolvidos com o grupo de estudos.

\section{Aplicação do Projeto}




\section{Primeiro Encontro}

Apresentação do grupo e dos participantes/professores envolvidos. A partir dos questionamentos sobre relações de gênero no contexto escolar propostos aos participantes, decidimos por mudar a ordem de aplicabilidade do projeto. Desta forma, partimos da elaboração das atividades pedagógicas por intermédio dos livros infantis dividindo a turma em dois grupos.

Atividade Proposta - elaborar uma atividade pedagógica para cada um dos livros propostos a fim de serem trabalhadas com crianças de 6 a 10 anos enfatizando, principalmente, as relações de gênero. Duração: 30 minutos para cada livro.

A atividade proposta teve por objetivo a atenção dada aos livros infantis em sala de aula por parte dos professores. A partir da leitura dos mesmos, os agentes deste projeto tiveram a intencionalidade de direcionar a questão de gênero no contexto escolar, demonstrando que mesmo a partir da leitura de pequenos livros infantis este assunto não apenas está presente, como pode e deve ser abordado para o não perpetuamento de preconceitos.

Atividades pedagógicas propostas pelos participantes:

\section{Grupo 1}

Atividade 1 - livro "Cabelinhos nuns lugares engraçados": pedir que os alunos falem brincadeiras de meninos e brincadeiras de meninas que serão listadas pelo professor no quadro. Depois trabalhar a reflexão, desconstruindo idéias pré-concebidas que descriminam e geram preconceito.

Atividade 2 - livro "Mamãe botou um ovo": pedir que a classe desenhe o que entendem que é ser menino e ser menina. Trabalhar conforme a atividade 1, ou seja, trabalhar a reflexão da temática gênero, desconstruindo idéias pré-concebidas que descriminam e geram preconceito.

\section{Grupo 2}

Atividade 1 - livro "Mamãe botou um ovo": levantar o conhecimento das crianças sobre “nascer” através de um desenho; As crianças são incentivadas a falarem de seus desenhos. A professora lê o livro (o mesmo usado para a realização desta atividade) mostrando as figuras e tirando dúvidas. 
Dinâmica: 2 figuras grandes (na lousa) uma feminina e outra masculina. Trazer um rol de figuras de revistas com fita adesiva para grudar na lousa: bola, boneca, carro, cores, brinco, profissões, etc. Perguntar às crianças quais figuras seriam para meninos e quais seriam para meninas. Professora faz a discussão sobre gênero a partir da exposição e distribuição das figuras por parte dos alunos.

Atividade 2 - livro “Cabelinhos nuns lugares engraçados”: professora lê o livro mostrando as figuras. Esta encaminha a discussão para as transformações biológicas (pelos, odores, espinhas, voz...) e psicológicas (como eu estou me sentindo? Como me vejo? Como penso que o outro me vê?) que as crianças estão notando.

Dinâmica: dar para cada um uma folha repartida em quatro onde deverão desenhar (sem precisar por o nome): eu bebê; eu hoje; eu adulto; eu idoso. Colocar a classe em círculo, apresentar cada desenho e interpretar junto com a classe, questionando e refletindo as questões de gênero.

\section{$\underline{\text { Segundo Encontro }}$}

Na semana seguinte nos reunimos com os mesmos participantes e fizemos uma discussão reflexiva sobre as atividades propostas pelos mesmos na semana anterior. Em seguida foi realizada uma análise de gênero dos dois livros, demonstrando página por página questões e situações que poderiam ser abordadas pelos professores em sala de aula.

Em seguida partimos para a abordagem conceitual de Gênero e Sexualidade propostos no projeto a partir de Foucault e Scott. Assim, partindo da teoria, fizemos uma discussão prática das relações de gênero no contexto escolar com a intersecção de situações reais do diaa-dia desta instituição, tomando como base o livro "Meninas e meninos na escola: um encontro possível?”.

\section{Resultados e conclusões}

Pensamos que falar de sexualidade e relações de gênero é instigante, mas também complexo. Essa complexidade pôde ser vista no curto momento trocado com os professores durante este projeto, cujos olhares de interpretação foram múltiplos, mas nunca simplistas.

Na fala das professoras, enquanto avaliação deste projeto: 
Analisando o ponto de vista aplicativo de como introduzir temas sexuais e de gênero em sala de aula com meninos e meninas, o cuidado ou mesmo o material a ser introduzido deverá ser muito cauteloso, no como trabalhar ou até mesmo falar. As orientações que recebi nesses encontros foram altamente produtivas.

[...] abriram leques temáticos de gênero suficientes no procedimento pedagógico. [...] Encontramos tudo isso nos temas transversais, que a educação sexual deve ser explorada, mas cabe a cada educador orientar enfocando dimensões sociológicas, psicológicas e fisiológicas da sexualidade.

Os documentos educacionais divulgam que a sexualidade deve ser tratada como fonte de vida, no entanto, o que averiguamos é a afirmação desta como um tópico pontual, presente em projetos que objetivam o controle da gravidez na adolescência e a prevenção de doenças, com ênfase no uso de preservativo, inculcando nos sujeitos um caráter negativo atribuído às manifestações sexuais. Igualmente, as relações de gênero também se encontram nestes documentos, porém acabam por se manifestar negativamente, quando as diferenças sociais são perpetuadas como naturais, causando resultados desastrosos na vida de meninos e meninas, o que, de certa forma, culmina na desigualdade entre os sexos.

O processo de constituição social das identidades sexuais e de gênero se dá no âmbito das instituições sociais, como exemplo, a escola. Neste contexto, é impossível negar a manifestação dessas identidades nos espaços escolares, como também a atuação dos/as professores/as sobre esta. No tocante deste projeto, pudemos vislumbrar que uma simples reflexão teve grande importância para esses profissionais, que perceberam no enfoque das temáticas possibilidades de prática diária perante seus alunos. Assim, não por menos, faz-se necessário prepararmos nossos/as educadores/as para agirem conscientemente sobre as manifestações de sexualidade e relações de gênero que ocorrem em suas salas de aulas objetivando, desta forma, a construção e desenvolvimento de cidadãos integrais. 


\title{
SEXUALITY, GENDER AND EDUCATION: NEW LOOKS
}

\begin{abstract}
This research intends to display the importance and necessity of the formation of professionals of the education how much to the thematic ones on sexuality, sort relations and its understanding in the pertaining to school context. It was objectified to sensitize and to generate questionings of professors of the Net of Education being taken them to reflect it the description-social and changeable character of the cited concepts of the thematic ones. From pedagogical workshop with these professionals one promoted presentations theoretical, exposition and quarrel of worked daily situations to the pertaining to school scope related the thematic ones. Leaving of the understanding that sexuality and sort are description-social constructions, it was considered that these two instances are inside of the educational institution, being that the existing social relations in the school produce representations of sexuality and sort relations that must be analyzed so that it doesn't occur the perpetuation of preconceptions and stereotypes that generate negative situations between boys and girls. Thinking on these questions, it was perceived necessity of formation in thematic of sexuality and the sort relations for people who act directly with education and deal in the daily pertaining to school with impediments related to these thematic ones. From these interventions one noticed that the majority of the participants obtained to reflect on the raised questions exceeding the biological vision not only, but perceiving in the approach of the thematic ones, possibilities of practical daily in the pertaining to school scope.
\end{abstract}

KEYWORDS: Sexuality. Gender. Sexual Guidance. School.

\section{REFERÊNCIAS}

COLE, B. Cabelinhos nuns lugares engraçados. Tradução de Lenice Bueno da Silva. São Paulo: Ática, 1999.

Mamãe botou um ovo. Tradução de Lenice Bueno da Silva. São Paulo: Ática, 1993.

COSTA, A. P.; RIBEIRO, P. R. M. Sexualidade e relações de gênero: a formação docente em questão. In: CONGRESSO INTERNACIONAL FAZENDO GÊNERO, 8., 2008, Florianópolis. Anais...Florianópolis: Mulheres, 2008. 1 CD-ROM.

FIGUEIRÓ, M. N. D. (Org.). Homossexualidade e educação sexual: construindo o respeito à diversidade. Londrina: UEL, 2007.

. O professor como educador sexual: interligando formação e atuação profissional. In: RIBEIRO, P. R. M. (Org.). Sexualidade e educação: aproximações necessárias. São Paulo: Arte \& Ciência, 2004. p.115-151. 
FOUCAULT, M. História da sexualidade I: a vontade de saber. Tradução de Maria Thereza da Costa Albuquerque e J. A Guilhon Albuquerque. Rio de Janeiro: Graal, 1988.

FREIRE, P. Pedagogia da autonomia: saberes necessários à prática educativa. São Paulo: Paz e Terra, 1998. (Coleção Leitura).

LOURO. G. L. Pedagogias da sexualidade. In: LOURO, G. L. (Org.). O corpo educado: pedagogias da Sexualidade. Belo Horizonte: Autêntica, 2000. p.09-34.

MAIA, A. C. B. Orientação sexual na escola. In: RIBEIRO, P. R. M. (Org.). Sexualidade e educação: aproximações necessárias. São Paulo: Arte \& Ciência, 2004. p.153-179.

MELO, S. M. M. de; POCOVI, R. M. de S. Educação e sexualidade. Florianópolis: UDESC, 2002. (Caderno Pedagógico, v.1).

RIBEIRO, P. R. M.; REIS, G. V. dos. Sexualidade e educação escolar: algumas reflexões sobre orientação sexual na escola. In: MAIA, A. C. B.; MAIA, A. F. Cadernos CECEMCA: educação infantil: sexualidade e educação infantil. Bauru: Ed. da UNESP, 2005. p.20-26.

SCOTT, J. Gênero: uma categoria útil de análise histórica. Educação e Realidade, Porto Alegre, v.20, n.2, p. 05-19, jul./dez. 1995.

SOUZA, F. C. Meninas e meninos na escola: um encontro possível? Porto Alegre: Zouk, 2006.

WEEKS, J. O corpo e sexualidade. In: LOURO, G. L. (Org.). O corpo educado: pedagogias da sexualidade. Belo Horizonte: Autêntica, 2000. p.37-82. 